\title{
The Money Consensus: What Do People Really Think of the Monetary System? And Does it Influence Ethical Decision-Making?
}

\author{
Chris Macdonald ${ }^{1 *}$ \\ ${ }^{1}$ Skylab, United Kingdom \\ *Corresponding author: Chris Macdonald: chrismacdonald@dr.com
}

\section{OPEN ACCESS}

Citation: Macdonald C. (2020) The Money Consensus: What Do People Really Think of the Monetary System? And Does it Influence Ethical Decision-Making? Open Science Journal 5(3)

Received: $15^{\text {th }}$ February 2020

Accepted: $12^{\text {th }}$ June 2020

Published: $6^{\text {th }}$ August 2020

Copyright: (c) 2020 This is an open access article under the terms of the Creative Commons Attribution License, which permits unrestricted use, distribution, and reproduction in any medium, provided the original author and source are credited.

Funding: The author received no specific funding for this work

Competing Interests: The author has declared that no competing interests exist.

\begin{abstract}
:
Recent experiments have revealed that the mere thought of money can decrease ethical decision-making. This paper explores the underlying mechanisms of this phenomenon by investigating how the modern generation feels about the monetary system. Data from US and UK participants revealed that over $80 \%$ felt that money is one of the leading reasons why people make unethical decisions. The general consensus included that the invention of money has been mainly bad for the environment, plants, and wildlife, and that humans would have more authentic relationships and be happier and more ethical if money had never been invented. The findings offer valuable insight into why thoughts of money can loosen our morals.
\end{abstract}

Keywords: Ethics, Morality, Monetary system, Money, Ethical decisionmaking, Psychology, Sociology, Economics

\section{Introduction}

The idea that money can have a negative influence on ethical judgement can be found in the earliest examples of literature (i.e The Epic of Gilgamesh, 2100 $\mathrm{BCE})$. And since then, it has echoed throughout the ages, be it through the condemnations of religious texts and the aphorisms of ancient philosophers or the chorus of a pop song and the quip of a TV personality.

Many of those who saw it necessary to relay a warning of money didn't mince their words. In the King James version of the bible, it claims that "it is easier for a camel to go through the eye of a needle, than for a rich man to enter into the kingdom of God" (Matthew 19:24). And perhaps more well known, it warns that "the love of money is the root of all evil" (Timothy 6:10). In an ancient text rich with discrete codes and subtle metaphors, the amplitude of these unrepentant lines is particularly brazen. The camel is the complete entity of one of the largest 
common 'tools' of the time, and the eye of the needle is a mere fraction of one of the smallest common tools of the time. 'The root of all evil' goes even further with regard to hyperbole as each word is absolute. Rather than 'an unhealthy fixation with some aspects of money may be one of the factors behind some unethical decisions', it goes boldly for the love of money is the root of all evil.

Guru Nanak, the founder of Sikhism, was also rather direct and unapologetic when condemning money. He stated that the accumulation of money "cannot be done without ceasing to be virtuous or without committing sins and social evils" (Gandhi, 2007).

The condemnation of money can also be found in Buddhism. In the Brahmajāla Sutta-a sacred Buddhist document-there is a definitive list of that which an enlightened one must abstain from, and in addition to the behavior we might expect to see condemned, such as permitting slavery or killing others, it also includes the mere acceptance of money (Digha Nikaya 1).

In ancient Rome the message reappears from the lips of Cicero who warned that "nothing is so secure as that money will not defeat it" (Cordry, 2015). In ancient Greece, Plato declared that "all wars are fought for the sake of getting money" (Avalos, 2005). And in ancient China, Confucius noted that while "the superior man understands what is right; the inferior man understands what will sell" (Bald, 2014).

Jumping forward to more recent times, we can find harsh criticisms of money in popular music, from some of the most respected songwriters, spanning many eras and genres:

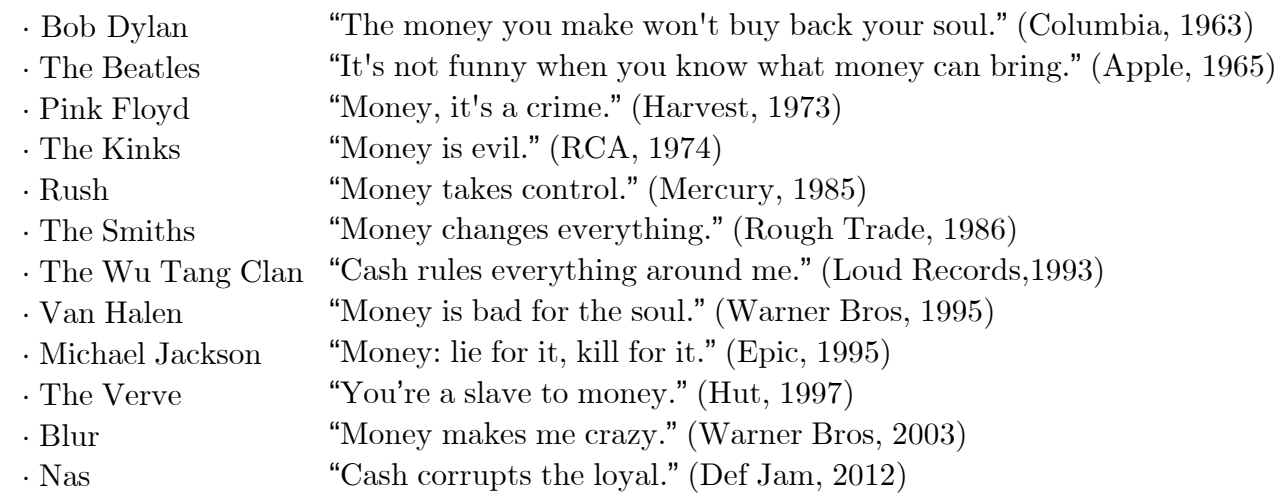

In fact, it seems that this idea has found its voice through every popular medium. Sapiens, a book that spent over 100 weeks on the bestsellers' list, warns that "money brings down the dams of community" (Harari, 2014). In a recent news article, renowned reporter Stuart Jeffries stated that "money has corrupted us" (Jeffries, 2014). And in Key to the City, Stephen Fry, one of the most respected TV presenters of our age, stated that "there is something about the sheer presence of money that brings about something very puzzling and dark within us" (Fry, 2013).

And so, while it does it appear to be a relatively popular opinion among key figures, does it mirror the opinion of the general public? Do people really believe that money is responsible for 'evil' deeds and that it has the power to corrupt the mind? Is there a consensus? 
One could logically assume that hyperbolic statements may travel further than a more conservative general opinion. Besides, money has evolved a great deal in (relatively) recent years. We have gone from paper notes backed by gold to plastic cards backed by loans, and on the horizon, we have the emergence of various forms of cryptocurrency. What's more, we have further reason to potentially reimagine the monetary system in a significant manner due to the current rates of national debt and the rapid rise of automation.

However, while recent developments and previous criticisms may inspire obtaining a modern-day consensus, there is another valid reason to get an understanding of what people truly think about the monetary system.

A number of recent studies have not only shown that accumulated wealth can result in a reduction of ethical decision-making (Johns et al, 2010; Piff et al, 2012; Wang et al, 2014) but so too can the mere thought of money (Gino et al, 2009; Kouchaki et al, 2013; Vohs, 2015; Macdonald, 2019). The hope is that better understanding public opinion of money can help us understand the underlying mechanisms behind this phenomenon.

Therefore, there are three questions this paper explores: What does the modern generation think of money? Is there a consensus? And, do the answers to these questions help us understand why the mere thought of money appears to trigger a decrease in ethical standards?

\section{Experiment 1}

It has previously been shown that when primed with the idea of money, participants are more likely to make unethical decisions (Gino et al, 2009; Kouchaki et al, 2013; Macdonald 2019). In Experiment 1, I wanted to investigate the opinions of one of the populations involved in these studies: US Students. In particular, I wanted to learn more about their opinions of the monetary system as a whole and how money impacts specific areas relevant to ethical decisions. The idea being that this could offer valuable insight as to why the mere thought of money can impact ethical judgement.

\section{Participants}

100 US Students took part in the experiment. In an attempt to reduce variables all participants also had the following in common: aged 18-25, caucasian ethnicity, and English-only spoken at home. All participants were paid to take part in the experiment.

\section{Procedure}

Each randomly selected participant was given access to a private online portal where they could complete an anonymous survey. Each participant was reminded that there is no right or wrong answer and that they should give their honest unfiltered opinion.

The first question sought after unrestricted qualitative responses, and so the participants were asked to list the first three words that come to mind when they think about the monetary system. The following 7 questions were targeted to ethically-relevant sectors of life such as health, politics, defense, and the environment, and the participants were asked to consider how each area had been 
positively or negatively affected by money. The remaining 6 questions explored how participants felt certain aspects of life would be different if money had never been invented.

\section{Results}

Qualitative data

When asked to list three words that come to mind when thinking of the monetary system, $62 \%$ of participants gave a word that indicated a negative opinion whereas only $5 \%$ of participants gave a word that indicated a positive opinion. The remaining $33 \%$ of participants gave three words that could not be clearly identified as indicating a positive or negative opinion (such as fame, religion, and complicated).

The most common words were money (which appeared 14 times), words containing capital such as capitalism and capitalist (which appeared 13 times), words containing greed, such as greed and greedy (which appeared 11 times), and words containing corrupt, such as corrupt and corruption (which appeared 9 times).

The two most populated subcategories were words that suggest the idea of unfairness (greed 9, greedy 2, corrupt 7, unfair 6, unequal 3, unbalanced 2, skewed 2, biased 2, etc) and words that signify a form or unit of currency (money 14, cash 7 , dollar 5, fiat 4, paper 3 , credit 3 , green 3 , dollars 2 , coin 2 , coins 2 , etc).

$5 \%$ of the participants used profanities and $4 \%$ used two or more words to form a negative statement (such as "it's, absolutely, awful").

While there are some significant trends, there is also great diversity across the responses with $9 \%$ of the words only used twice and $58 \%$ of the words being totally unique.

Quantitative data

The next section of the survey required one of two answers: mainly good or mainly bad. Participants were told that if they felt the answer could be both good and bad, then they should select the option with the higher percentage. Below is each question with the responses given as percentages:

Do you feel that the invention of money has been mainly good for democracy or mainly bad for democracy?

Mainly good $69 \%$ Mainly bad $31 \%$

Do you feel that the invention of money has been mainly good for the environment, plants, and wildlife or mainly bad for the environment, plants, and wildlife?

Mainly good 13\% Mainly bad $87 \%$

Do you feel that the invention of money has been mainly good for world peace or mainly bad for world peace?

Mainly good 26\% Mainly bad $74 \%$

Do you feel that the invention of money has been mainly good for physical health or mainly bad for physical health? 
Mainly good $47 \%$ Mainly bad $53 \%$

Do you feel that the invention of money has been mainly good for mental health or mainly bad for mental health?

Mainly good 16\% Mainly bad $84 \%$

Do you feel that the invention of money has been mainly good for sustainability or mainly bad for sustainability?

Mainly good $45 \%$ Mainly bad $55 \%$

Do you feel that the invention of money has been mainly good for equal opportunity or mainly bad for equal opportunity?

Mainly good $29 \%$ Mainly bad $71 \%$

The final section of the questionnaire includes some modifications to the question structure and vocabulary. This was done to reduce possible unwanted variables and influences such as the order effect (Lavrakas, 2008). In the previous section, the response that implied a negative view of money was offered second, whereas now it is offered first. The previous questions required the answer of good or bad, whereas now the questions require the answer of yes or no. The number of questions has also been changed as have the order of the themes.

Once again, the participants were reminded that if they felt the answer could be either option, then they should select the one with the higher percentage. Below is each question with the responses given as percentages:

Do you feel that the natural world (the environment, plants, and wildlife) would be better off if money had never been invented?

Yes $79 \%$ No $21 \%$

Do you feel that humans would socialize more if money had never been invented? Yes $51 \%$ No $49 \%$

Do you feel that humans would have more genuine relationships if money had never been invented?

Yes $70 \%$ No $30 \%$

Do you feel that humans would be happier if money had never been invented? Yes $71 \%$ No $29 \%$

Do you feel that humans would be more ethical if money had never been invented?

Yes $73 \%$ No $27 \%$

Do you feel that money is one of the leading reasons why people do unethical things?

Yes $82 \%$ No $18 \%$ 


\section{Experiment 2}

Experiment 2 also investigates the modern opinion of the monetary system, but this time with another population: UK Students. This enables multinational comparison and thus offers further insight as to why the mere thought of money can impact ethical judgement.

\section{Participants}

100 UK Students took part in the experiment. In an attempt to reduce variables all participants also had the following in common: aged 18-25, caucasian ethnicity, and English-only spoken at home. All participants were paid to take part in the experiment.

\section{Procedure}

As with Experiment 1, each randomly selected participant was given access to a private online portal where they could complete an anonymous survey. Each participant was reminded that there is no right or wrong answer and that they should give their honest unfiltered opinion. They were then given exactly the same questions and instructions as used in Experiment 1.

\section{Results}

Qualitative data

When asked to list three words that come to mind when thinking of the monetary system, $54 \%$ of participants gave a word that indicated a negative opinion whereas $0 \%$ of participants gave a word that indicated a positive opinion. The remaining $46 \%$ of participants gave three words that could not be clearly identified as indicating a positive or negative opinion (such as bank, cash, and circular).

The most common words were words containing capital such as capitalism and capitalist (which appeared 13 times), unfair (which appeared 12 times), cash (which also appeared 12 times), and words containing pound such as pound and pounds (which appeared 11 times).

The two most populated subcategories were words that suggest the idea of unfairness (unfair 12, greed 9, corrupt 5, unequal 4, scam 2, punishing 2, exploitative 2, exploitation 2 , biased 2 , etc) and words that signify a form or unit of currency (cash 12, money 10, pound 8, dollar 6 , coins 5 , etc).

$2 \%$ of the participants used profanities and only $1 \%$ used two or more words to form a statement ("life, is, expensive").

While there are some significant trends, there is also great diversity across the responses with $7 \%$ of the words only used twice and $56 \%$ of the words being totally unique. 
Quantitative data

The next section of the questionnaire required one of two answers, mainly good or mainly bad. Below is each question with the responses given as percentages:

Do you feel that the invention of money has been mainly good for democracy or mainly bad for democracy?

Mainly good $63 \%$ Mainly bad $37 \%$

Do you feel that the invention of money has been mainly good for the environment, plants, and wildlife or mainly bad for the environment, plants, and wildlife?

Mainly good $18 \%$ Mainly bad $82 \%$

Do you feel that the invention of money has been mainly good for world peace or mainly bad for world peace?

Mainly good $21 \%$ Mainly bad $79 \%$

Do you feel that the invention of money has been mainly good for physical health or mainly bad for physical health?

Mainly good 50\% Mainly bad 50\%

Do you feel that the invention of money has been mainly good for mental health or mainly bad for mental health?

Mainly good 14\% Mainly bad $86 \%$

Do you feel that the invention of money has been mainly good for sustainability or mainly bad for sustainability?

Mainly good $48 \%$ Mainly bad $52 \%$

Do you feel that the invention of money has been mainly good for equal opportunity or mainly bad for equal opportunity?

Mainly good $27 \%$ Mainly bad $73 \%$

The final section of the survey also required one of two answers, this time, either yes or no. Below is each question with the responses given as percentages:

Do you feel that the natural world (the environment, plants, and wildlife) would be better off if money had never been invented?

Yes $79 \%$ No $21 \%$

Do you feel that humans would socialize more if money had never been invented? Yes $51 \%$ No $49 \%$

Do you feel that humans would have more genuine relationships if money had never been invented?

Yes $69 \%$ No $31 \%$

Do you feel that humans would be happier if money had never been invented?

Yes $74 \%$ No $26 \%$ 
Do you feel that humans would be more ethical if money had never been invented?

Yes $86 \%$ No $14 \%$

Do you feel that money is one of the leading reasons why people do unethical things?

Yes $83 \%$ No $17 \%$

\section{Discussion}

For the final discussion, we return to the set of questions posed before launching the experiments and see how the data can assist in responding to them.

Questions 1 and 2: What does the modern generation think of money? Is there a consensus?

In the quantitative data there was high levels of concordance between both populations (average difference $<4 \%$ ). Overall the majority of participants indicated a negative opinion of the monetary system. There were 8 questions in particular where $70 \%$ or higher selected the negative option:

1. $70 \%$ of US participants and $69 \%$ of UK participants feel that humans would have more genuine relationships if money had never been invented

2. $71 \%$ of US participants and $73 \%$ of UK participants feel that the invention of money has been mainly bad for equal opportunity

3. $71 \%$ of US participants and $74 \%$ of UK participants feel that humans would be happier if money had never been invented

4. $79 \%$ of US participants and $79 \%$ of UK participants feel that the natural world (the environment, plants, and wildlife) would be better off if money had never been invented

5. $73 \%$ of US participants and $86 \%$ of UK participants feel that humans would be more ethical if money had never been invented

6. $82 \%$ of US participants and $83 \%$ of UK participants feel that money is one of the leading reasons why people do unethical things

7. $87 \%$ of US participants and $82 \%$ of UK participants feel that the invention of money has been mainly bad for the environment, plants, and wildlife

8. $84 \%$ of US participants and $86 \%$ of UK participants feel that the invention of money has been mainly bad for mental health

Therefore, when considering both populations, the consensus appears to be that the invention of money has been mainly bad for the environment, plants, and wildlife, and our own equal opportunities. The consensus also appears to be that humans would have more authentic relationships and be happier and more ethical if money had never been invented.

And more generally, one could say that participants are more likely to associate money with a negative word than a positive word. 
Question 3: Do the results help us understand why the mere thought of money appears to trigger a decrease in ethical standards?

Disconnection and the Gilgamesh effect

A known phenomenon in psychology is that priming participants with the theme of human disconnection increases the likelihood of unethical decisionmaking, known as the Gilgamesh Effect (Macdonald, 2020a; Macdonald, 2020b; Macdonald, 2020c). This has previously been linked with money priming, as participants primed with money noted a decreased sense of authentic human connection (Macdonald, 2019). Therefore, one of the reasons why the mere thought of money can trigger a decrease in ethical decision-making may be the Gilgamesh Effect.

The results revealed in this paper offer valuable insight as to why money might trigger a decreased sense of authentic human connection. The quantitative data revealed that $70 \%$ of US participants and $69 \%$ of UK participants felt that humans would have more genuine relationships if money had never been invented. The qualitative data revealed that words signifying a form or unit of currency quickly come to mind when thinking of money (cash, dollar, coins, etc), and as noted by Professor Kathleen Vohs et al, if money can trigger a marketpricing mode where people think with regard to transactions, "then one might expect problems when it comes to socially relating to others" (Vohs et al, 2008).

Feeling less of an authentic connection to others may decrease the time spent considering how decisions may impact others, which could help to explain why there is an increase in unethical decisions.

Self-focus, scarcity, and dissatisfaction

Another psychological phenomenon that fits with the data can be found in the work of economist James Harvey. In 2011, Harvey released a paper demonstrating that ethical people tend to be more satisfied with life (Harvey, 2011). And the results reported here indicate that thinking of money may decrease one's sense of life satisfaction.

One of the reasons to suspect this is that participants were more likely to associate money with a negative word than a positive word, which may result in a less positive outlook. Furthermore, the consensus appears to be that many specific aspects of life would be better off if money had never been invented. Thus it is reasonable to suggest that reminders of money may result in a decreased satisfaction with the current state of affairs, and therefore the participants may be less satisfied with one's own life.

The data also offers the possibility of a more direct route to a decreased sense of life satisfaction. The two most populated subcategories of words noted by participants were words that suggest forms or units of currency (cash, money, dollars, etc), and words that suggest the idea of unfairness (unfair, unequal, exploitation, etc), thus perhaps the participants were contemplating their own financial situation and were not particularly happy about it.

One of the reasons this might be the case is due to the current data on financial pressure and instability. The average US student graduates with over $\$ 35,000$ of debt (Hess, 2018), and the average UK student graduates with a debt of over $£ 50,000$ (Coughlan, 2017). In addition to this, 70\% of UK workers either said that their finances where permanently precarious or that they were not managing to get by (Hill, 2018), and $78 \%$ of US full-time workers are living 
paycheck-to-paycheck (Manning-Schaffel, 2017). This is significant when we consider that financial security strongly relates to life satisfaction (Howell et al, 2013). Particularly when additional resources are needed to satisfy basic physiological needs (known as Need Theory).

Therefore the results suggest that ideas of money may trigger participants to look internally at their current misfortunes, and this could explain the increase in unethical activity. In other words, the potential reward of an unethical action may be perceived as greater when primed with the idea of money.

Justification and excusability

The results also suggest that participants with money on the mind may have greater accessibility to the idea that other people are less ethical. For example, the consensus appeared to be that humans would be more ethical if money had never been invented, which suggests the idea that people are not as ethical as they could be.

There are other indications that also highlight a possible mistrust in others, such as the frequency of words relating to unfairness and the idea that people may have less authentic relationships as a result of money. The combination of these thoughts could promote unethical actions. For example, if a participant feels that a significant number of people are making unethical decisions then there may be the perception of fewer consequences for unethical actions. In other words, the thought of money may remind a participant of the unethical actions of others, and as a result, unethical actions may be perceived as more justifiable by comparison.

This logic is in line with the work of Shalvi et al who suggest that justifications can decrease anticipated threats as well as increase the perception that a given decision is excusable in context (Shalvi et al, 2015). Excusability plays a key role in immoral behavior as people generally strive to maintain a positive self-image, even when there is no risk of being found out (Allport, 1955; Rosenberg, 1979; Shalvi et al, 2015).

\section{Compounding components}

The theories suggested thus far could complement each other in several ways.

A common model used when deciphering unethical decisions is the idea of risk versus reward. The data reported here offers the possibility that when participants are primed with the idea of money there may well be a compounding effect: an increased value placed upon possible rewards and a decreased sense of potential risks.

The potential reward may appear greater when participants are self-focused, less satisfied with life, and reminded of possible scarcity. The potential negative consequences to one's self may appear to decrease when one can justify unethical decision-making by comparing it to the unethical behavior of others. And the potential negative consequences to others may be less apparent when one feels less authentically connected.

In short, when considering risk versus reward before potentially making an unethical decision, participants primed with money may view the reward as more tempting and the risks as less damaging or more acceptable.

While one all-inclusive theory can be appealing, the results suggest that there are multiple mechanisms at work, and therefore it is wise to expect that there 
may be a great deal more to discover. As we often suspect through scientific inquiry, separateness may be an illusion of perspective. That is to say that when we pull out a single 'culprit', it appears to be part of a complicated web of interconnections.

The combination of complementary mechanisms helps to explain the potency of the phenomenon. It also highlights the human vulnerability to indirect external influences.

Further explorations could consider cultural variations and mitigating primes.

\section{Concluding remarks}

Even when scientifically studying the potential consequences of the monetary system, one can be met with frustration. A common response is that money is simply a tool, one that can be used for good or bad, and therefore nothing is inherently negative about it. While money could be viewed as a simple tool, as with any creation it influences us in many ways, and it may facilitate or even promote unexpected yet undesirable outcomes.

The smartphone is also a tool, and likewise one could make the case that it could be used for good or bad. However, with the smartphone, we have the enormous benefit that we have experienced life before it was invented and life after it has become ingrained into society. Having the personal experience of witnessing how it appeared to change us led to some significant scientific inquiries. In line with popular assumptions, research has now linked smartphones to increased depression (Alhassan et al, 2018), loneliness (Jiang et al, 2018), stress, and anxiety (Vahedi et al, 2018).

This healthy criticism of the new tool prompted further studies which revealed less apparent insights. For example, researchers from the University of Waterloo found a link between heavy smartphone usage and decreased analytic thinking (Barr et al, 2015). And reachers from the University of Chicago found that the mere presence of a smartphone can significantly impede available cognitive capacity (Ward et al, 2017).

Perhaps our generation will be motivated by these observations to warn our children and their children to be cautious of smartphones. Perhaps we will attempt to remind them of ways of life before this new technology. However, as generations go by, the warnings may lose their potency and a life without smartphones may seem almost unimaginable. A time when you step away from the screen and chat face-to-face on a daily basis might one day appear as outdated as sending smoke signals.

With money, we don't have the same benefit of prior experience. We were born into a society that has been saturated with money for thousands of years. As we haven't directly experienced a way of life before it, we may have missed the most valuable insights and the strongest warnings. Perhaps the ancient condemnations of the monetary system are the faded echos of those who lived in a time before money. Perhaps they witnessed first hand that the invention of money transformed our perspectives, as formally unwise decisions could now be justified if profitable. Maybe we became less satisfied with life and more selffocused. Perhaps we started to form less authentic relationships. Maybe the new tool facilitated isolated power and promoted unsustainable and unethical decisions. 
Perhaps those before us predicted that with the invention of an infinitely stockpileable resource, our systems would begin to conflict with planetary limits. Perhaps they foresaw that with new powerful incentives we might become atomized units of an economy rather than valued members of a supportive community.

Maybe they feared that we would become so focused on profit that we may inadvertently begin to steal the future from our own children. Maybe they feared that money would one day become so ingrained into our daily lives that we couldn't even imagine a way of life without it. Maybe their biggest fear of all was that there would come a time when we would no longer question it.

\section{References:}

Alhassan AA, Alqadhib EM, Taha NW, Alahmari RA, Salam M, Almutairi AF. 2018. The relationship between addiction to smartphone usage and depression among adults: a cross sectional study. BMC Psychiatry 18:(1) 148 doi.org/10.1186/s12888-018-1745-4

Allport GW. 1955. Becoming: Basic considerations for a psychology of personality. New Haven, CT: Yale University Press

Apple. 1965. If You've Got Trouble by The Beatles, written by Lennon-McCartney

Avalos H. 2005. Fighting Words: The Origins of Religious Violence. New York: Prometheus. 40

Bald M. 2014. Literature Suppressed on Religious Grounds. New York: Facts On File. 13

Barr N, Pennycook g, Stolz JA, Fugelsang JA. 2015. The brain in your pocket: Evidence that Smartphones are used to supplant thinking. Computers in Human Behavior 45: 473-480 doi.org/10.1016/j.chb.2015.02.029

Columbia. 1963. Masters of War by Bob Dylan, written by Dylan B

Cordry HV. 2015. The Multicultural Dictionary of Proverbs. North Carolina: McFarland \& Company. 179

Coughlan, S. 2017. Student debt rising to more than $£ 50,000$. BBC News March 28th 2018 bbc.com/news/education-40493658

Def Jam. 2012. A Queens Story by Nas. Written by Nas

Digha Nikaya 1. Brahmajāla Sutta. DN 1, March 25th 2009 dhammatalks.org/suttas/DN/DN01.html

Epic. 1995. Money by Michael Jackson, written by Jackson M

Fry, 2013. Key to the City. UK: ITV

Gandhi S S. 2007. History of Sikh Gurus Retold: 1469 - 1606. New Delhi: Atlantic Publishing. 187

Gino F, Pierce L. 2009. The abundance effect: Unethical behavior in the presence of wealth. Organizational Behaviour Human Decision Processes 109:(2) 142-155 psycnet.apa.org/record/2009-10822-005

Harari YN. 2014. Sapiens: A brief history of humankind. London: Vintage Books. 208

Harvest. 1973. Money by Pink Floyd, written by Waters R.

Harvey JS. 2011. Is the Just Man a Happy Man? An Empirical Study of the Relationship between Ethics and Subjective Well-Being. Kyklos 64:(2) 193-212 http://dx.doi.org/10.1111/j.14676435.2011.00502.x

Hess, A. 2018. Here's how much the average student loan borrower owes when they graduate. CNBC March 28th 2018 cnbc.com/2018/02/15/heres-how-much-the-average-student-loan-borrower-oweswhen-they-graduate.html

Hill, A. 2018. Seven in 10 UK workers are 'chronically broke'. The Guardian March 27th 2018

theguardian.com/money/2018/jan/25/uk-workers-chronically-broke-study-economic-insecurity)

Howell RT, Kurai M, Tam L. 2013. Money Buys Financial Security and Psychological Need Satisfaction: Testing Need Theory in Affluence. Social Indicators Research 110:(1) 17-29 https://doi.org/10.1007/s11205-010-9774-5

Hut. 1997. Bitter Sweet Symphony by The Verve, written by Ashcroft R

Jeffries S. 2014. Money has corrupted us. We no longer understand what it's worth. The Guardian March 28th 2019 theguardian.com/money/2014/jan/01/money-corrupted-us-understand-worth

Jiang Q, Li Y, Shypenka V. 2018. Loneliness, Individualism, and Smartphone Addiction Among International Students in China. Cyberpsychology, Behavior, and Social Networking 21 (11) doi.org/10.1089/cyber.2018.0115

Johns A, Slemrod J. 2010. The Distribution of Income Tax Noncompliance. National Tax Journal 63:(3) 397-418 
Kouchaki M, Smith-Crowe K, Brief AP, Sousa C. 2013. Seeing green: Mere exposure to money triggers a business decision frame and unethical outcomes. Organizational Behaviour Human Decision Processes 121:(1) 53-61 dx.doi.org/10.1016/j.obhdp.2012.12.002

Lavrakas, PJ. 2008. Encyclopedia of Survey Research Methods. California: Sage Publications

Loud Records. 1993. C.R.E.A.M by Wu-Tang Clan, written by Diggs R, Hunter J, Smith C, Woods C.

Manning-Schaffel, V. 2017. Most of Us Live Paycheck-to-Paycheck. NCB News March 27th 2018

nbcnews.com/better/health/most-us-live-paycheck-paycheck-what-it-does-your-health-ncna816411

Matthew 19:24. The Holy Bible. March 28th 2019 bible.com/bible/1/MAT.19.KJV

Macdonald C. 2019. Money, a disconnecting agent: Reminders of money trigger a feeling of disconnection which increases the likelihood of unethical decisions. Open Science Journal 4:(1) 110 doi.org/10.23954/osj.v4i1.2200

Macdonald C. 2020a. Lexicon Connection Priming and Ethics: As our sense of human connection decreases, so too does ethical decision-making. The Open Science Journal 5:(1) 1-7 doi.org/10.23954/osj.v5i1.2276

Macdonald C. 2020b. Graphical Connection Priming and Ethics: As our sense of human connection decreases, so too does ethical decision-making. The Open Science Journal 5:(1) 1-6 doi.org/10.23954/osj.v5i1.2275

Macdonald C. 2020c. The Gilgamesh Effect: The ethical consequences of disconnection. The Open Science Journal 5:(2) 1-6 doi.org/10.23954/osj.v5i2.2316

Mercury. 1985. The Big Money by Rush, written by Peart N, Lifeson A, Geddy L

Piff PK, Stancato DM, Cóté S, Mendoza-Denton R, Keltner D. 2012. Higher social class predicts increased unethical behavior. Proceedings of the National Academy of Sciences 109:(11) 40864091 doi.org/10.1073/pnas.1118373109

RCA. 1974. Preservation by The Kinks, written by Davies R

Rosenberg M. 1979. Conceiving the self. New York, NY: Basic Books

Rough Trade. 1986. Money Changes Everything by The Smiths, written by Morrissey

Shalvi S, Gino F, Barkan R, Ayal S. 2015. Self-Serving Justifications: Doing Wrong and Feeling Moral. Current Directions in Psychological Science 24:(2) 125-130 doi.org/10.1177/0963721414553264

Timothy 6:10. The Holy Bible. March 28th 2019 bible.com/bible/1/1TI.6.KJV

Vahedi Z, Saiphoo A. 2018. The association between smartphone use, stress, and anxiety: A meta analytic review. Wiley 34:(3) 347-358 https://doi.org/10.1002/smi.2805

Vohs KD, Mead NL, Goode MR. 2008. Merely activating the concept of money changes personal and interpersonal behavior. Current Perspectives in Psychological Science 17:(3) 209 doi.org/10.1111/j.1467-8721.2008.00576.x

Vohs KD. 2015. Money Priming Can Change People's Thoughts, Feelings, Motivations, and Behaviors: An Update on 10 Years of Experiments. Journal of experimental psychology General 144:(4) e86-e93 dx.doi.org/10.1037/xge0000091

Wang L, Murnighan JK. 2014. Money, Emotions, and Ethics Across Individuals and Countries. Journal of Business Ethics 125: 163 doi.org/10.1007/s10551-013-1914-9

Ward A, Duke K, Gneezy A, BOS M. 2017. Brain Drain: The Mere Presence of One's Own Smartphone Reduces Available Cognitive Capacity. Journal of the Association for Consumer Research 2:(2) 140-154 doi.org/10.1086/691462

Warner Bros. 1995. Big Fat Money by Van Halen, written by Hagar S, Van Halen E 